\title{
Origem, distribuição e inserção dos nervos do plexo braquial em Araras Canindé (Ara ararauna, Linnaeus, 1758)
}

\author{
Kamal Achôa Filho ${ }^{1 *}$ \\ Marcio Nogueira Rodrigues ${ }^{2}$ \\ Erika Toledo da Fonseca ${ }^{2}$ \\ Rafael Magdanelo Leandro ${ }^{3}$ \\ Vanessa Bertagia Pasqualetti ${ }^{1}$ \\ Maria Angélica Miglino ${ }^{2}$

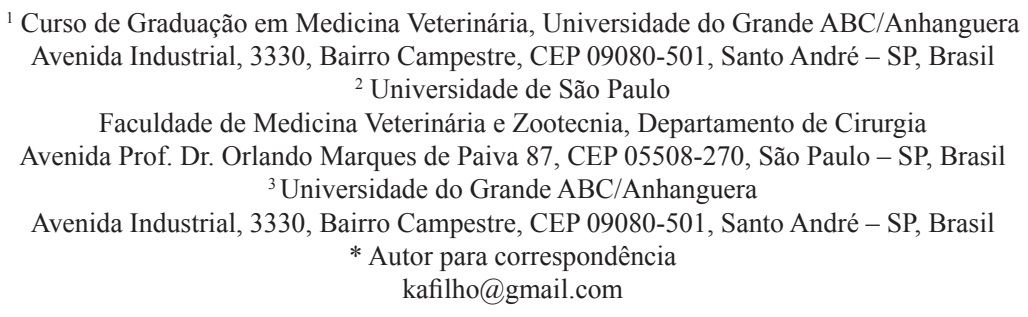

Submetido em 11/03/2014

Aceito para publicação em 05/06/2014

\section{Resumo}

O Brasil possui cerca de 80 espécies de psitacídeos catalogados, sendo cinco delas identificadas como Araras. Como na grande maioria das aves, as Araras têm como seu principal meio de locomoção o voo. No entanto, a força e o impulso gerado durante o ciclo do bater das asas exigem um mecanismo de controle ativo neuromuscular e adaptações especializadas dos músculos responsáveis pelo voo, que são inervados pelo plexo braquial. Este estudo visa a descrever a origem e distribuição dos nervos periféricos que compõem o plexo braquial da Arara Canindé (Ara ararauna, Linnaeus, 1758), a fim de auxiliar o médico veterinário a reconhecer e localizar lesões neuromusculares nessa espécie. Foram utilizados cinco cadáveres, provenientes do Centro de Triagem de Animais Silvestres da Paraíba, nos quais os nervos foram identificados mediante dissecação direta. Foram visualizadas quatro raízes nervosas, originando três troncos nervosos, que são provenientes dos espaços intervertebrais entre da décima vértebra cervical e a segunda vértebra torácica. Os nervos provenientes do cordão dorsal inervavam os músculos extensores, enquanto os nervos do cordão ventral inervavam os músculos flexores da asa, além dos ramos peitorais, responsáveis pela inervação dos músculos superficiais torácicos e do ombro.

Palavras-chave: Anatomia; Aves; Inervação; Psitacídeos; Sistema nervoso periférico

\section{Abstract}

Origin, distribution, and insertion of the brachial plexus nerves in Blue-and-yellow Macaws (Ara ararauna, Linnaeus, 1758). Brazil has about 80 species of parrots cataloged, and five of them are identified as 
Macaws. As the vast majority of birds, Macaws use flight as their primary means of locomotion. However, the strength and power generated during the cycle of beating wings require a mechanism of active neuromuscular control and specialized adaptations of muscles responsible for flight, which are innervated by the brachial plexus. This study aims to describe the origin and distribution of peripheral nerves that make up the brachial plexus in Blue-and-yellow Macaw (Ara ararauna, Linnaeus, 1758), in order to aid the veterinarian to recognize and locate neuromuscular lesions in this species. We used five dead bodies, obtained from the Screening Center for Wild Animals in Paraíba, Brazil, in which the nerves were identified by direct dissection. Four nerve roots were viewed, originating three nerve trunks, which stem from the intervertebral spaces between the tenth cervical vertebra and the second thoracic vertebra. Nerves from the dorsal cord innervated extensor muscles, while ventral cord nerves innervated flexor muscles of the wing, in addition to the pectoral branches, responsible to innervate the superficial thoracic and shoulder muscles.

Key words: Anatomy; Birds; Innervation; Parrots; Peripheral nervous system

\section{Introdução}

O Brasil possui um considerável número de espécies de psitacídeos catalogados, perfazendo cerca de 80 espécies, fato que levou nosso país a ser denominado desde os anos 1500, como a "Terra dos papagaios". Entre os psitacídeos mais conhecidos estão às Araras. Estas podem ser classificadas em Araras Azuis (Anodorhynchus hyacinthinus, Anodorhynchus leari), Araras Vermelhas (Ara macao e Ara cholopterus) e Arara Canindé (Ara ararauna), esta última, uma das mais populares do gênero, podendo ser encontrada em florestas nas diversas regiões brasileiras (SICK, 1997).

As Araras, como na maioria das aves, têm como principal meio de locomoção o voo (McLELLAND, 1990), sendo capazes de sincronizar a extensão das articulações do cúbito e punho da asa, usando mecanismos de coordenação automatizada que envolve adaptação esquelética e muscular. No entanto, a força e o impulso gerado durante o ciclo do bater das asas e a complexa cinemática da asa durante o movimento exigem um mecanismo de controle ativo neuromuscular e adaptações especializadas dos músculos do voo inervados pelo plexo braquial (STURKIE; WHITTOW, 2000).

Objeto de constantes estudos clínicos e cirúrgicos, o plexo braquial é formado por estruturas compostas de fibras nervosas simpáticas, responsáveis pela inervação da musculatura envolvida no movimento das asas. É diretamente relacionado aos diagnósticos de disfunções neuromusculares provenientes de processos traumáticos, infecções, neoplasias e infestações por ácaros e vírus (BAUMEL, 1981).

Para Bolson et al. (2005), as fraturas em aves de vida livre podem ser ocasionadas por vários fatores. Um dos mais frequentes são os acidentes com obstáculos impostos pelo homem como os fios de luz ou telefone, cercas, telas, grades e vidros que refletem árvores. $\mathrm{O}$ tráfico de animais silvestres colabora com a incidência de injúrias por meio das tentativas de captura com instrumentos como cordas e redes.

Segundo Bush (1977), as fraturas que ocorrem em ossos longos são mais comuns, destacando-se as fraturas umerais. Devido à proximidade do nervo com a diáfise do osso e a pequena quantidade de musculatura presente na região, à ruptura do nervo radial ocorre com grande incidência nas fraturas umerais, dificultando o bom prognóstico do tratamento clínico ou cirúrgico (BOLSON et al., 2005).

Pode ocorrer também a avulsão dos nervos do plexo braquial. Neste caso o dano pode ser permanente incluindo falta da percepção da dor, atrofia dos músculos e paralisia com perda de reflexos. Esse tipo de lesão é mais comum em aves em vida livre, do que em aves de cativeiro (RITCHIE, et al., 1994).

O conhecimento anatômico do plexo braquial é importante na realização de procedimentos anestésicos, locais ou regionais, que objetivam potencializar o efeito analgésico durante o período pré e transoperatórios (HOCKING, et al., 1997). Não é raro o relato de intervenções cirúrgicas realizadas de maneira inadequada resultando em prognóstico desfavorável devido ao 
desconhecimento da anatomia de animais silvestres (FRANCESCHI et al., 2009).

\section{Material e Métodos}

Os animais utilizados neste trabalho vieram a óbito por causas naturais, sendo provenientes do CETAS PB e foram doados congelados ao setor de Anatomia dos Animais Domésticos e Silvestres da Faculdade de Medicina Veterinária e Zootecnia da Universidade de São Paulo. Foram dissecadas cinco araras (Ara ararauna, Linnaeus, 1758) previamente fixadas com solução aquosa de formaldeído a $4 \%$. O projeto foi aprovado pela Comissão de Ética no Uso de Animais da FMVZ - USP sob o número 2619/2012.

Procedeu-se a dissecação da origem do plexo braquial dos espécimes e da distribuição dos nervos com auxílio de instrumental básico de dissecação. Fez-se necessária uma incisão para rebatimento do tegumento e tela subcutânea da região axilar e da asa. Posteriormente, realizou-se uma incisão transversal dos músculos peitoral superficial e profundo, próximo ao esterno e quilha, expondo e individualizando os nervos que compõem o plexo braquial. Os troncos nervosos foram individualizados próximos à coluna vertebral, para observação dos ramos ventrais dos nervos espinhais cervicais e torácicos. Após a identificação dos nervos, os arranjos foram esquematizados e fotografados para documentação, seguindo a nomenclatura de acordo com o descrito por Baumel et al. (1993).

\section{Resultados}

Os espécimes apresentaram em ambos antímeros três troncos nervosos compondo seu plexo braquial, originando-se da porção ventral dos nervos espinhais entre a décima vértebra cervical $(\mathrm{C} 10)$ e a segunda vértebra torácica (T2). As raízes que compõe os troncos nervosos estavam situadas entre a décima vertebra cervical (C10) e a segunda vertebra torácica (T2) (Figura 1).

O primeiro tronco nervoso, proveniente dos espaços intervertebrais $\mathrm{C} 10$ a C11, foi o único a emitir nervos antes da fusão das raízes nervosas. Os nervos identificados foram: romboide, esternocoracoide e supracoracoide (Figura 1), antes de transpassar o músculo peitoral profundo. Após o músculo peitoral profundo (Figura 2), observou-se bilateralmente o início dos cordões nervosos, ventral e dorsal.

A partir da fusão das raízes, formou-se um tronco único, que se subdividiu entre cordões ventral, dorsal e um ramo que originou os nervos subcoracoide,

FIGURA 1: Fotomacrografia das origens do plexo braquial. Estão identificadas a origem dos troncos nervosos do plexo, (A, B, C e D) que formam um calibroso ramo antes da divisão $(E)$ entre nervo peitoral $(F)$, cordão ventral $(G)$ e cordão dorsal $(H)$ do antímero direito. Podem ser observados o nervo subcoracoide (I), nervo subescapular (J), nervo subcoracoescapular (K), nervo cutâneo do braço (L), nervo supracoracoide $(\mathrm{M})$, nervo romboide $(\mathrm{N})$ e o nervo esternocoracoide $(\mathrm{O})$. Barra de escala $1 \mathrm{~cm}$.

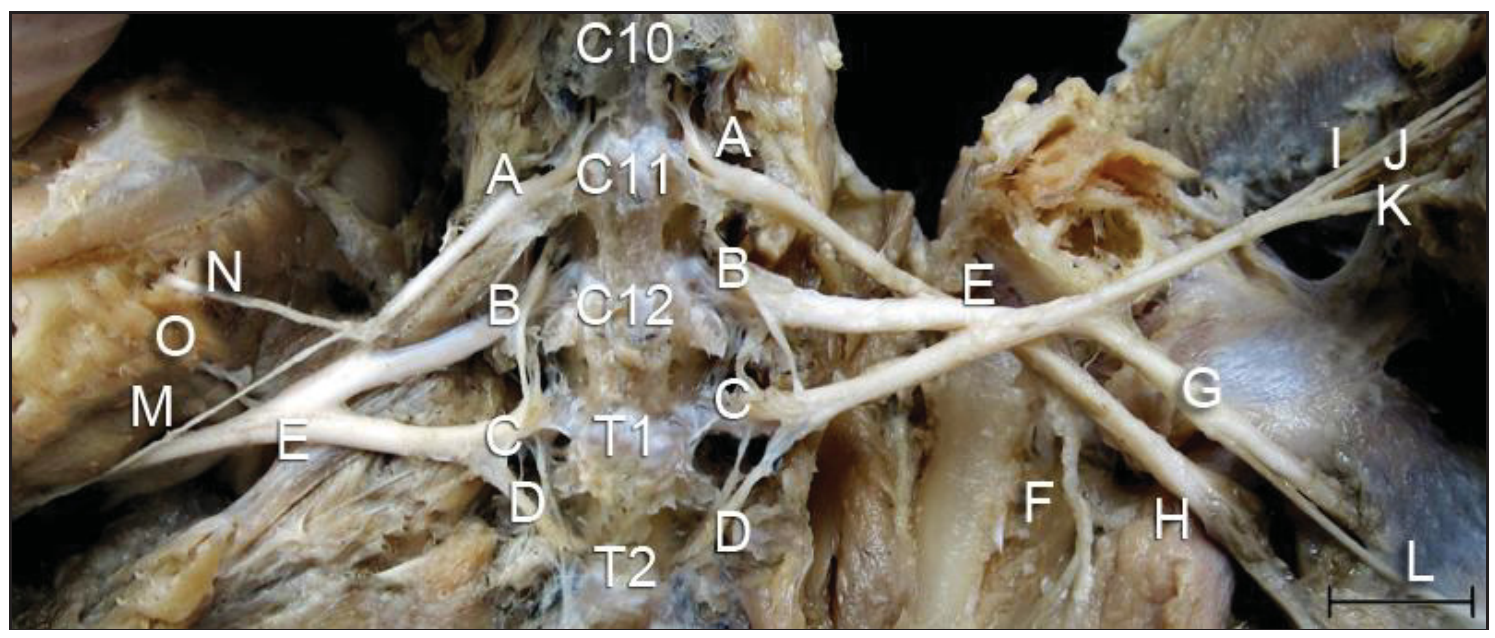


FIGURA 2: Fotomacrografia mostrando os troncos nervosos transpassando o músculo peitoral profundo. Estão identificados os troncos nervosos (A), músculo peitoral profundo (B), nervo supracoracoide (C), nervo subcoracoide (D), nervo subescapular (E) e subcoracoescapular (F). Barra de escala $1 \mathrm{~cm}$.

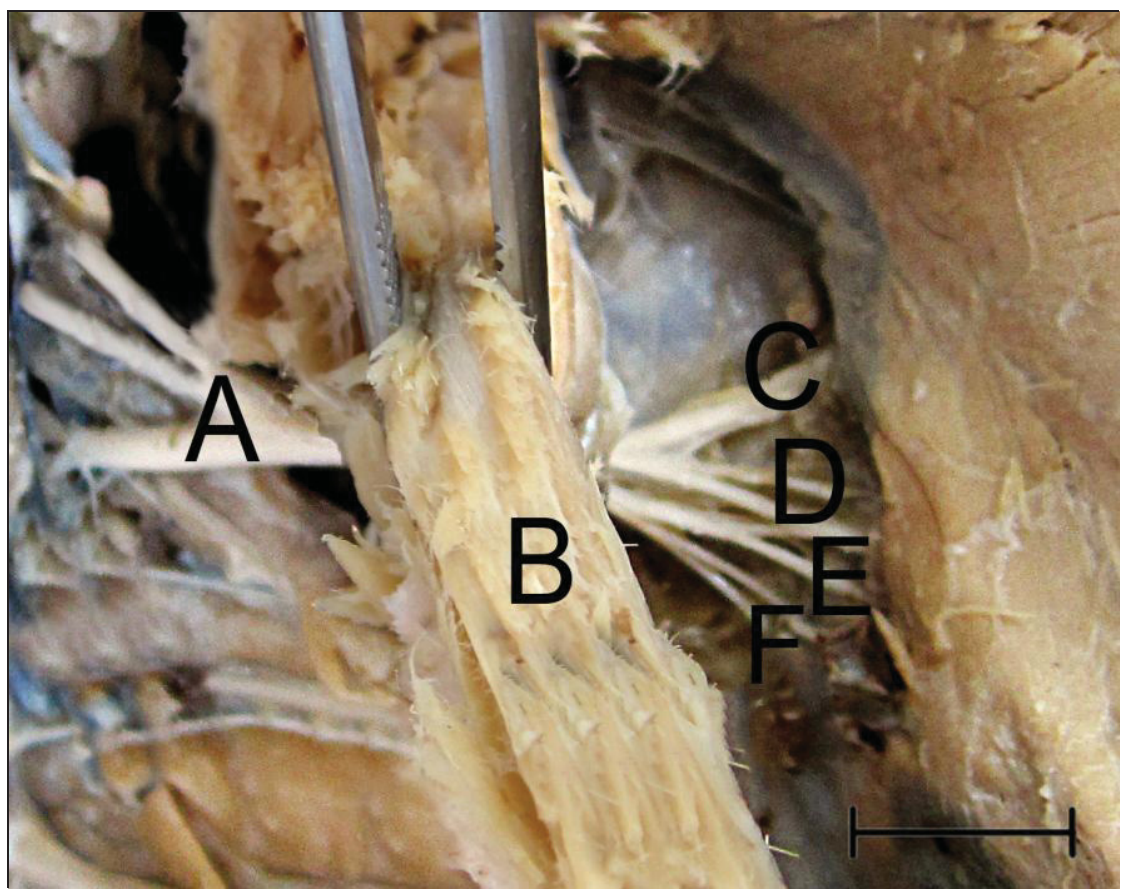

FIGURA. 3: Fotomacrografia demostrando a origem dos nervos a partir dos cordões dorsal e ventral. A partir da divisão dos troncos nervosos (A), estão identificados o cordão dorsal (B), cordão ventral (C), nervo peitoral (D), nervo medianoulnar (E), nervo cutâneo do braço (F), nervo axilar (G), nervo anconal (H), nervo subescapular (I) e o nervo subcoracoescapular (J). Barra de escala $1 \mathrm{~cm}$.

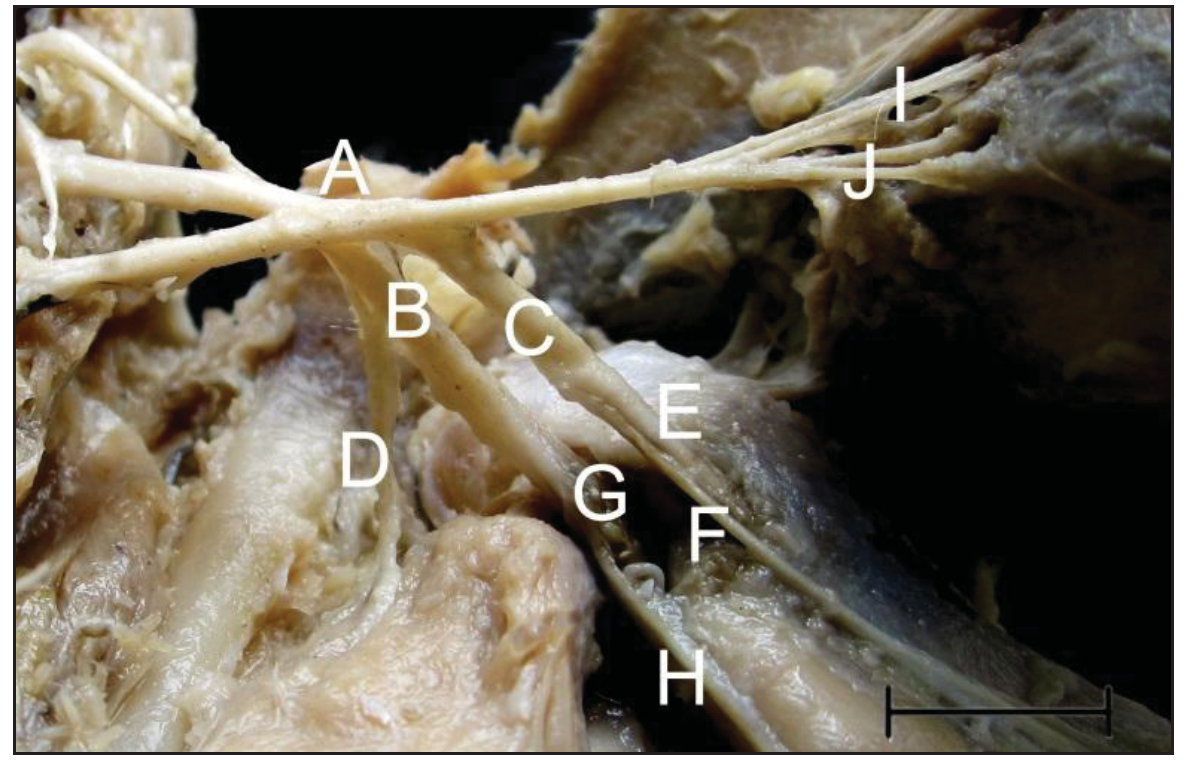


subescapular, subcoracoescapular, nervo cutâneo do braço e do nervo peitoral (Figura 3).

O cordão dorsal mostrou uma ramificação inicial que originava o nervo axilar e ventralmente o nervo anconal (Figura 3). Medialmente foi observado o início do nervo radial, que penetra de maneira profunda o braço dos espécimes estudados.

$\mathrm{Na}$ distribuição dos nervos do cordão ventral emergiam os nervos coracobraquial, bicipital e medianoulnar. Para melhor visualização do nervo coracobraquial, que inervava o músculo coracobraquial, o nervo foi sobreposto à musculatura, onde se pôde notar um ramo articular emitido pelo nervo medianoulnar (Figura 4).

Em sua porção mais proximal, o nervo medianoulnar originava o nervo bicipital (Figura 5) e continuava seu trajeto distal até os tendões propatagiais, onde se dividia em nervo mediano e nervo ulnar. O nervo mediano (Figura 6) se originava na região da fossa cubital inervando o músculo braquial e a articulação úmeroradio-ulnar. Pequenos ramos inervavam as extremidades

FIGURA 4: Fotomacrografia da distribuição nervosa da região do braço. Observar que o nervo medianoulnar (1) percorre a porção mais cranial dos músculos escapulotríceps braquial (a) e úmerotríceps braquial (c), seguindo caudalmente pelo o músculo bíceps braquial (b) e pelo úmero (d). Divide-se (4) entre nervo ulnar (5), que passa superficialmente pelo músculo pronador superficial (e) e o nervo mediano (6), que penetra na região mais profunda do antebraço. O nervo coracobraquial (2) e Ramo articular (3) foram sobrepostos sobre o bíceps braquial (b) para melhor visualização. Barra de escala $1 \mathrm{~cm}$.

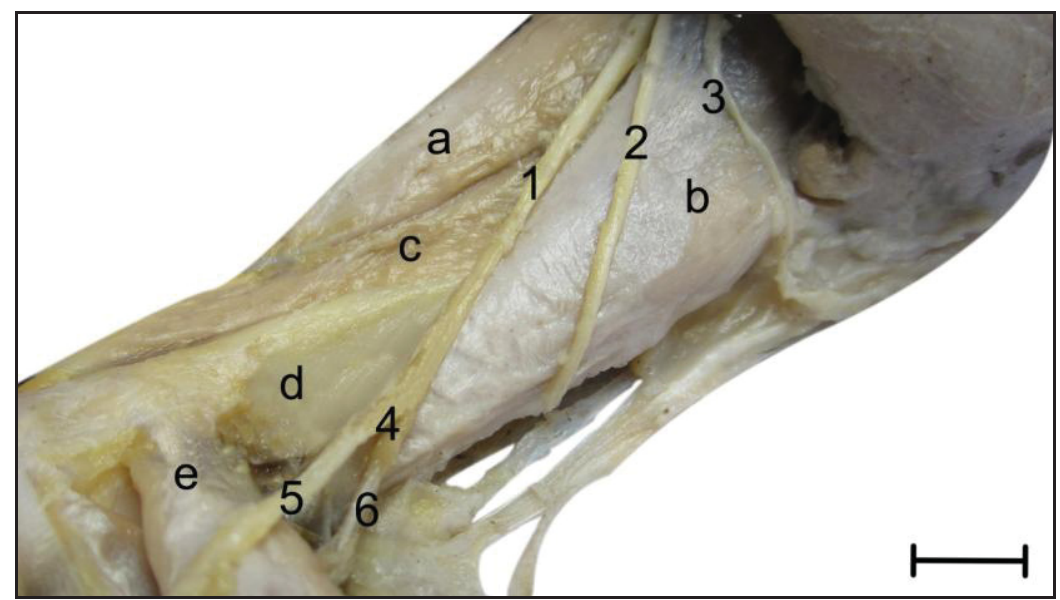

FIGURA 5: Fotomacrografia da inervação da região proximal do braço. Observar o nervo bicipital (1) originando-se do nervo medianoulnar (2) e inserindo-se no músculo bíceps braquial (a). Barra de escala $1 \mathrm{~cm}$.

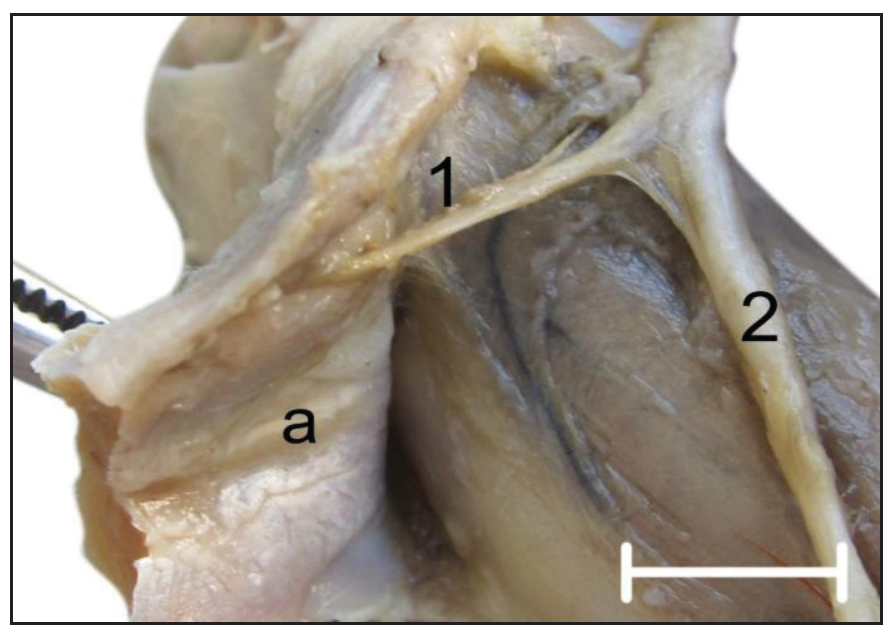


proximais dos músculos pronadores superficial e profundo. Seguindo seu caminho distal, o nervo mediano apresentou ramos superficial e profundo, suprindo os músculos: flexor digital superficial e profundo, ulnometacárpico ventral, abdutor digital maior e flexor digital superficial. Foi notado que a partir do nervo mediano surgia o nervo propatagial ventral (Figura 6).
Na divisão do nervo medianoulnar (Figura 6) o nervo ulnar seguia pela face medial do antebraço, emitindo ramificações para o músculo flexor ulnar do carpo e seguindo com seus ramos caudal e cranial região metacárpica das araras (Figura 7). O ramo cranial do nervo ulnar mostrou-se responsável pela inervação dos músculos interósseo ventral, flexor digital menor

FIGURA 6: Fotomacrografia da inervação do braço e antebraço. Observar o nervo medianoulnar (1) seguindo o músculo bíceps braquial (a). O nervo mediano (3) emite o nervo propatagial ventral (4), que segue a superfície medial do músculo extensor radial do metacarpo (b). O nervo ulnar (2) caminha superficialmente pelos músculos pronadores superficial (c) e profundo (d). Barra de escala $1 \mathrm{~cm}$

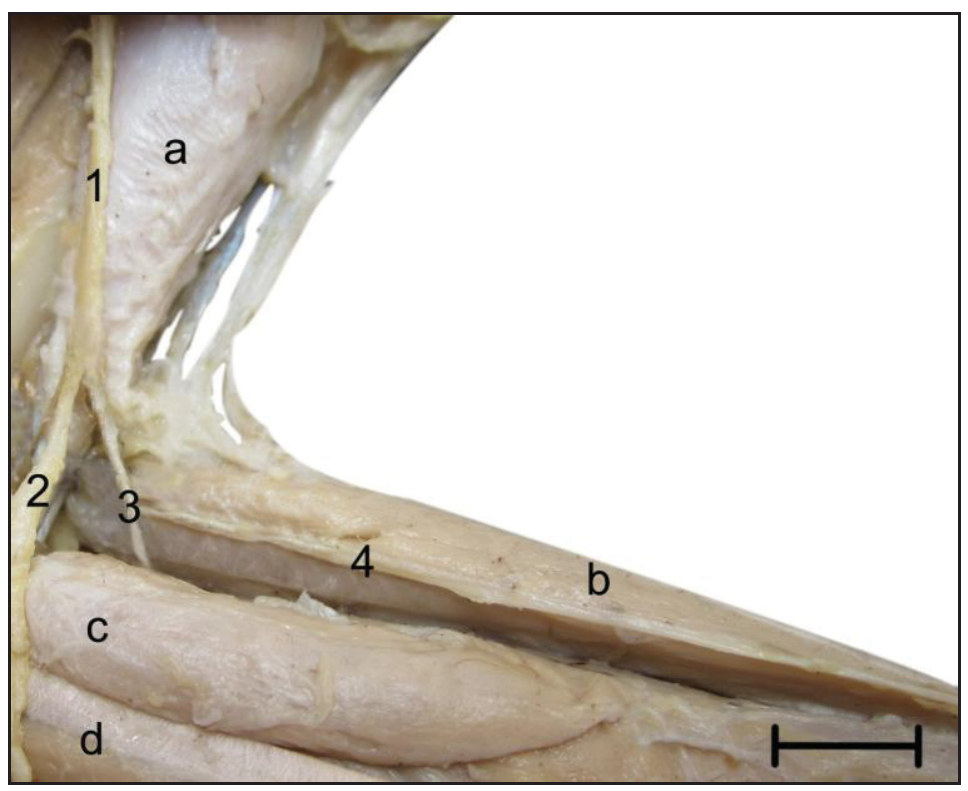

FIGURA 7: Fotomacrografia da inervação do antebraço. Observar nervo ulnar (1) e seus ramos: cranial (2), caudal (3) e ramo para o músculo flexor do carpo (4). Barra de escala $1 \mathrm{~cm}$.

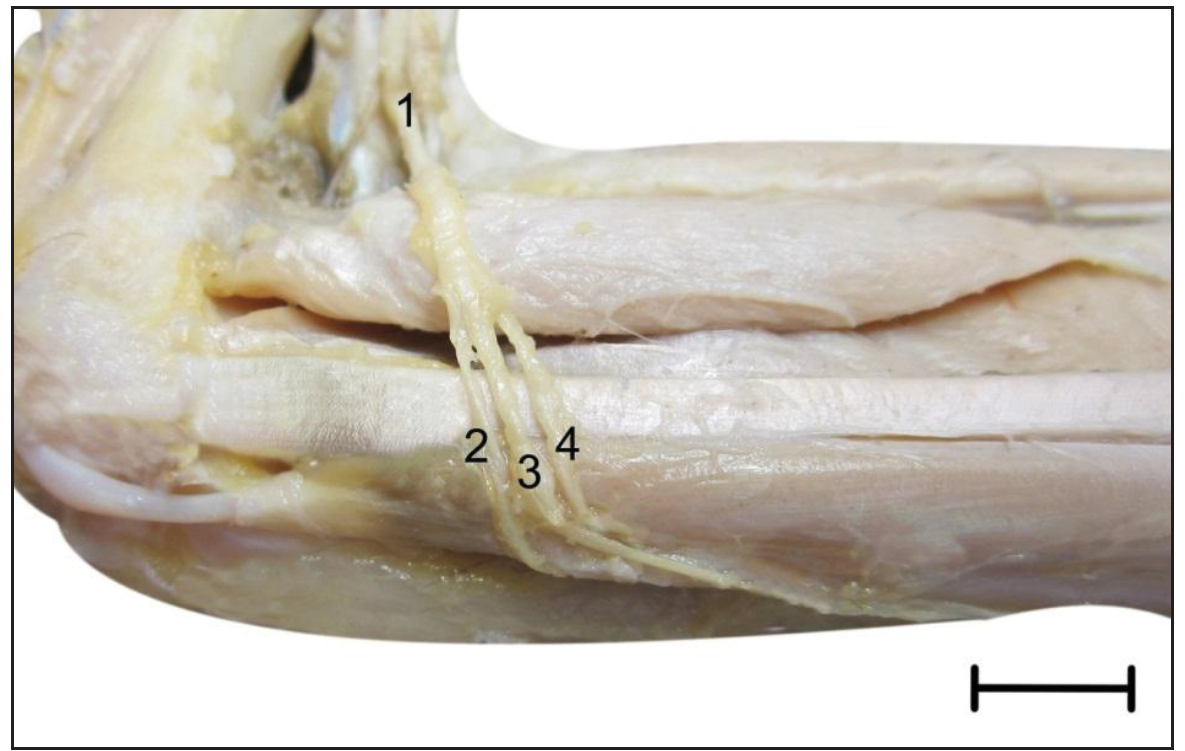


e articulações do metacarpo. O ramo caudal do nervo ulnar percorria o músculo flexor ulnar do carpo, onde emitiu ramos no antebraço que inervavam os folículos das penas secundárias e primárias.

Do cordão dorsal observou-se a formação do nervo axilar, que através do seu ramo proximal era responsável por inervar a articulação omal e músculos deltoides maior e menor. O nervo anconal separava-se do cordão dorsal caudalmente ao inicio do nervo radial, seguindo distalmente pela borda caudal do músculo escapulotríceps, enviando ramos nervosos para o mesmo e também para o músculo umerotríceps e para a articulação do cúbito (Figura 8).

O nervo radial era proveniente do cordão dorsal do plexo braquial, cranialmente ao nervo anconal. O nervo partia inicialmente da face medial seguindo para a face lateral, inserindo-se entre os músculos umerotríceps braquial e escapulotríceps braquial (Figura 9), com sua localização subcutânea próxima à porção distal do úmero (Figura 10).

FIGURA 8: Fotomacrografia da inervação da região do ombro. Observar o nervo medianoulnar (1), ramo nervoso (2) para o músculo bíceps braquial (b), passagem do nervo radial (3) pelo músculo umerotríceps braquial (a) e ínicio no nervo anconal (4). Barra de escala $1 \mathrm{~cm}$.

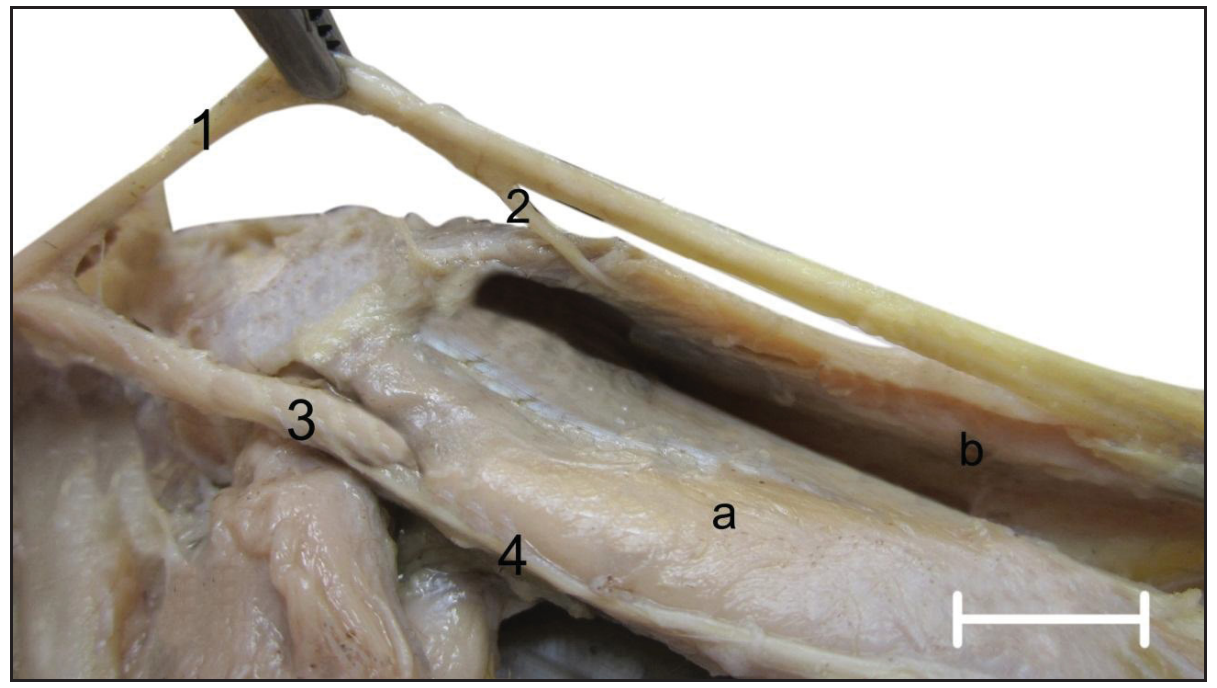

FIGURA 9: Fotomacrografia do nervo radial na região do braço. Observar passagem do nervo radial (1) pelos músculos umerotríceps braquial (a) e músculo escapulotríceps braquial (b) e o osso úmero (i). Barra de escala $1 \mathrm{~cm}$.

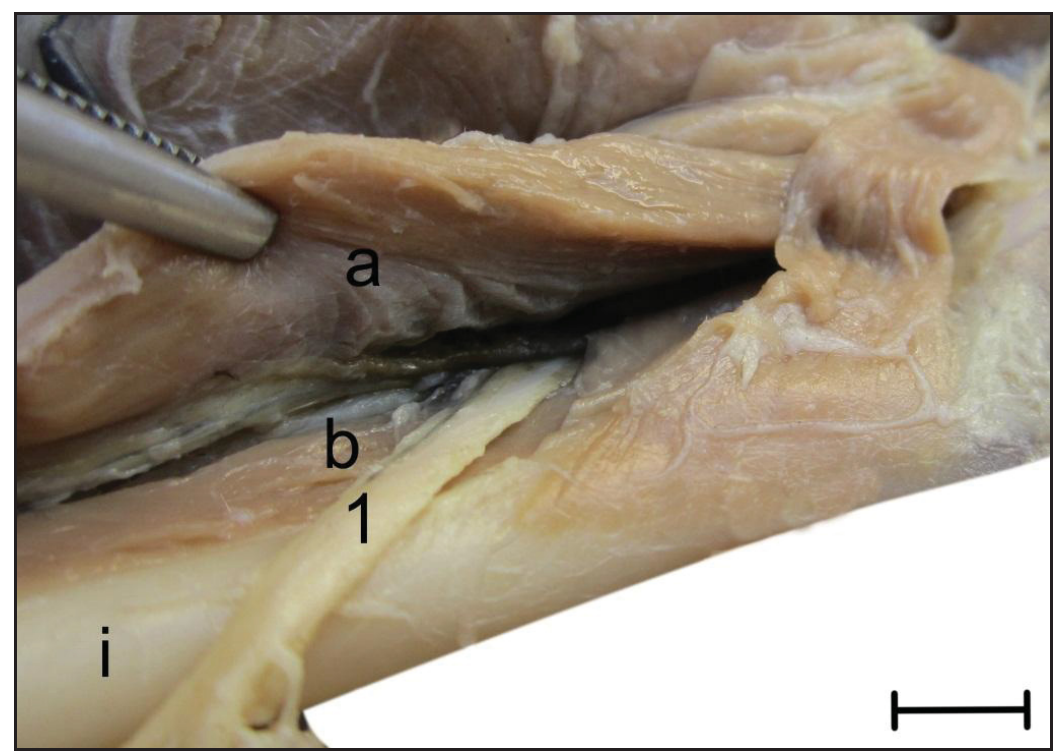


FIGURA 10: Fotomacrografia do braço e antebraço. Observar o nervo radial (1) em sua relação íntima com o úmero (a) e o início do nervo cutâneo do antebraço (2). Barra de escala $1 \mathrm{~cm}$.

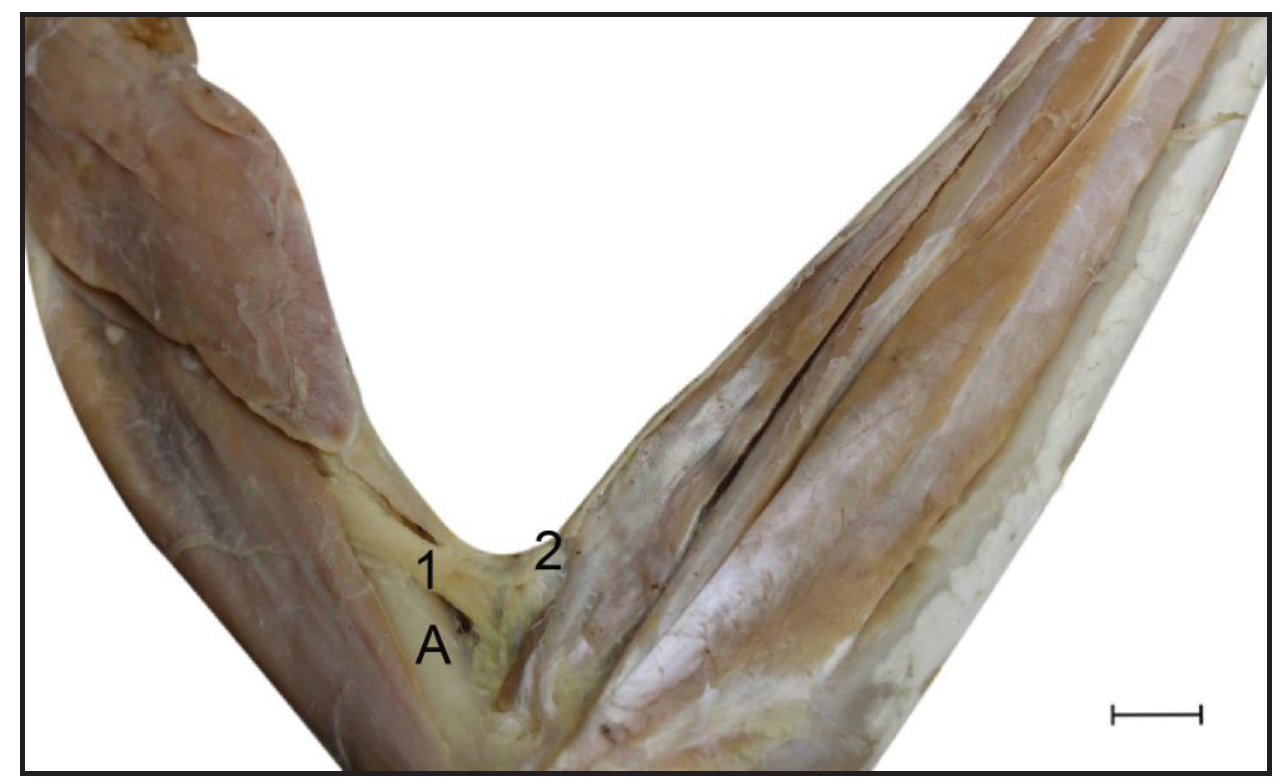

Antes de penetrar na fossa cubital, o nervo radial emitia dois ramos, o nervo cutâneo do antebraço e o nervo dorsal propatagial (Figura 10). Distalmente, a articulação do cúbito, emitia um ramo para o músculo extensor radial do metacarpo e outro para o músculo supinador.

Na porção proximal do antebraço, o nervo radial se dividia nos ramos superficial e profundo. $\mathrm{O}$ ramo superficial supria os músculos extensor digital comum, extensor ulnar do metacarpo e músculos extensor digital menor, inervando também folículos de penas. Seu ramo profundo supria os músculos extensor breve alular, interósseo ventral e dorsal.

\section{Discussão}

Com a popularização das aves, em especial os psitacídeos, a clínica aviária deparou-se com patologias específicas e ainda pouco estudadas no plexo braquial, como processos neoplásicos e traumatismos, além do aperfeiçoamento das técnicas de anestesia e denervação das asas, o que torna premente o estudo da neuroanatomia das Araras. Cardozo et al. (2009) estudaram a técnica de analgesia da asa em Galinhas (Gallus domesticus) através do bloqueio anestésico do plexo braquial, citando a necessidade do conhecimento anatômico da região, para o sucesso do procedimento

A importância clínica da localização e distribuição do plexo braquial pode ser percebida em relatos de casos citados por Murphy e Shivaprasad (2008), que descreveu dois casos de ganglioneuroma em Calopsitas (Nymphicus hollandicus), onde a formação tumoral aproximava-se do plexo braquial dos psitacídeos, promovendo ataxia, perda da habilidade de voo e dificuldade em empoleirarse. A sintomatologia clínica descrita neste estudo sugere que a origem dos cordões ventral e dorsal, assim como os nervos peitorais, foram afetados pelo tumor.

As informações a respeito da origem e inserção dos nervos que compõe o plexo braquial das Araras são escassas na literatura, portanto o presente trabalho faz uma análise anatômica comparativa com outras espécies de aves.

O plexo braquial dos exemplares estudados de Ara ararauna originou-se a partir de quatro de raízes nervosas provenientes das vértebras $\mathrm{C} 10$ a T2, formando os cordões dorsal e ventral, diferente do descrito em Perus por Moreira et al. (2005), onde o plexo originase em 3 raízes, provenientes das vértebras $\mathrm{C} 12$ a T2. A origem do plexo braquial em urubus ocorre a partir 
de quatro raízes nervosas provenientes das vértebras C11 e T2 (MOREIRA et al., 2009), que é semelhante ao encontrado nas araras estudadas. Yasuda (2004) comparou o plexo braquial de 16 subespécies de Galos (Gallus gallus), observando que houve variação no número de raízes nervosas. Dez subespécies apresentaram cinco raízes nervosas e seis subespécies demonstraram quatro raízes nervosas, sugerindo que pode ocorrer variação entre animais da mesma espécie.

De acordo com a topografia da musculatura da asa da Arara Canindé descrita por Achôa et al. (2014), observamos que a distribuição da inervação aferente para os grupos musculares extensores e flexores foram similares a outras espécies como Galos (BAUMEL, 1981) e Urubus (YASUDA, 2004).

Os nervos provenientes do cordão dorsal são: $\mathrm{n}$. axilar, n. anconal, n. radial, n. cutâneo do antebraço, n. propatagial dorsal, ramo profundo do n. radial e ramo superficial do n. radial, e são responsáveis pela inervação dos músculos extensores da asa. Já os nervos do cordão ventral, inervam os músculos flexores da asa, sendo eles: $n$. coracobraquial, n. bicipital, n. medianoulnar, $n$. mediano, n. propatagial ventral, ramo profundo do $n$. mediano, ramo superficial do n. mediano, n. ulnar, ramo cranial do n. ulnar, ramo caudal do n. ulnar.

Um detalhe importante observado quanto à distribuição dos nervos do plexo braquial foi a localização do nervo radial e medianoulnar. Ao transpassar da face medial para a lateral, o nervo radial encontra-se superficialmente ao úmero, sem proteção muscular, o que sugere uma fragilidade do sistema nervoso periférico das Araras, sendo susceptível a traumas e fraturas umerais. O nervo medianoulnar também está localizado superficialmente estando sujeito a lesões traumáticas, porém, não há relatos na literatura consultada sobre lesões neste nervo.

Devido a fácil exposição cirúrgica do nervo radial observada em nosso trabalho, a técnica de denervação do membro é uma alternativa para o controle do voo das aves residentes de parques e zoológicos para impedir seu voo em períodos de migração. Esta técnica é pouco invasiva e foi originalmente descrita por Baumel (1981). A técnica clássica de controle de voo é a amputação da mão das aves, também chamada de pinioning (SILVA et al., 2003).O pinioning é regulamentado no Brasil pelo Conselho Federal de Medicina Veterinária através da resolução 877 de 15 de fevereiro de 2008, anexo II, sendo permitido apenas em aves mantidas em instituições credenciadas pelo IBAMA, desde que não comprometa seu comportamento reprodutivo e que passem boa parte do seu tempo em solo ou água. Entretanto é uma técnica mais invasiva e gera maior morbidade no período pósoperatório.

Concluímos que a formação do plexo braquial em Araras Canindé (Ara ararauna) ocorre a partir de raízes nervosas provenientes dos espaços intervertebrais entre $\mathrm{C} 10$ a T2, apresentando três troncos nervosos que ao transpassar o músculo peitoral profundo, inicia a configuração dos cordões nervosos, dorsal e ventral. Os nervos provenientes do cordão dorsal das aves são responsáveis por inervar os músculos extensores e os nervos do cordão ventral são responsáveis por suprir os músculos flexores.

O conhecimento da neuroanatomia periférica das Araras é fundamental para o diagnóstico precoce de doenças que acometam o plexo braquial, cuja consequência principal é o prejuízo do voo, além de permitir a realização de técnicas anestésicas como bloqueio regional e melhor acesso cirúrgico para tratamento de fraturas em asas.

\section{Agradecimentos}

Agradecemos à Faculdade de Medicina Veterinária e Zootecnia da Universidade de São Paulo, pela oportunidade do estudo, à Fundação de Amparo à Pesquisa do estado de São Paulo (FAPESP), pelo apoio à nossa pesquisa, ao CETAS-PB pela doação dos cadáveres, à Exotic Pets Clínica Veterinária e a todos colaboradores envolvidos de forma direta e indireta no nosso trabalho.

\section{Referências}

ACHÔA FILHO, K.; LEANDRO, R. M.; RODRIGUES, M. N.; FONSECA, E. T.; PASQUALETTI, V. B.; MIGLINO, M. A. Musculatura da asa da Arara Canindé (Ara ararauna, Linnaeus, 
1758) conhecimento básico aplicado à clínica de animais silvestres. Biotemas, Florianópolis, v. 27, n. 2, 2014.

BAUMEL, J. J. Sistema nervoso das aves. In: GETTY, R. (Ed.). Sisson/Grossman: Anatomia dos animais domésticos. Vol. 2, 5. ed. Rio de Janeiro: Guanabara Koogan, 1981. p. 1890-1930.

BAUMEL, J. J.; BREAZILE, J. E.; EVANS, H. E.; KING, A. S.; VANDEN-BERGE, J. Handbook of avian anatomy: Nomina Anatomica Avium. 2. ed. Cambridge: Nuttal Ornithological Society, $1993.779 \mathrm{p}$.

BOLSON, J.; MACHADO, G.; ZEMBRZUSKI, F.; SCHOSSLER, J. E. Fratura umeral exposta e ruptura do nervo radial em coruja de orelha (Rhipnoptyns clamator). In: ENCONTRO DE ZOOLÓGICOS DO RIO GRANDE DO SUL, I, 2005, Cachoeira do Sul. Anais... Cachoeira do Sul: ONG Acaang, 2005. Versão eletrônica.

BUSH, M. External fixation of avian fractures. Journal of the American Veterinary Medical Association, Schaumburg, v. 171, n. 9, p. 943-946, 1977.

CARDOZO, L. B.; ALMEIDA, R. M.; FIÚZA, L. C.; GALERA, P. D. Brachial plexus blockade in chickens with $0.75 \%$ ropivacaine. Veterinary Anesthesia and Analgesia, Liverpool, v. 36, n. 4, p. 396-400, 2009.

FRANCESCHI, R. C.; STÜPP, S.; PEREIRA, M. A. M.; PROVENCI, M. Estudo da inervação e vascularização do membro torácico de Columba livia. Brazilian Journal of Veterinary Research and Animal Science, São Paulo, v. 46, n. 6, p. 507-514, 2009.

HOCKING, P. M.; GENTLE, M. J.; BERNARD, R.; DUNN, L. N. Evaluation of a protocol for determining the effectiveness of pretreatment with local analgesics for reducing experimentally induced articular pain in domestic fowl. Research in Veterinary Science, London, v. 63, n. 3, p. 263-267, 1997.
MCLELLAND, J. A colour atlas of avian anatomy. London: Wolfe, 1990. $127 \mathrm{p}$.

MOREIRA, P. R. R.; SOUZA, W. M.; SOUZA, N. T. M.; CARVALHO, R. G. Arranjos configurados pelos nervos do plexo braquial no urubu (Coragyps atratus foetens Linnaeus, 1758). Brazilian Journal of Veterinary Research and Animal Science, São Paulo, v. 46, n. 2, p. 144-151, 2009.

MOREIRA, P. R. R.; SOUZA, W. M.; SOUZA, N. T. M.; CARVALHO, R. G.; CUSTÓDIO, A. A. Arranjos configurados pelos nervos do plexo braquial no peru (Meleagris gallopavo Linnaeus, 1758), Ars Veterinária, Jaboticabal, v. 21, n. 3, p. 296302, 2005.

MURPHY, B. G.; SHIVAPRASAD, H. L. Ganglioneuroma of the brachial plexus in two cockatiels (Nymphicus hollandicus). Veterinary Pathology Online, California, v. 45, n. 5, p. 690-692, 2008.

RITCHIE, B. W.; HARRISON G. J.; HARRISON J. R. Avian Medicine: principles and application. Florida: Wingers Publishing, 1994. $397 \mathrm{p}$.

SICK, H. Ornitologia Brasileira. Edição revista e ampliada por José Fernando Pacheco. Rio de Janeiro: Nova Fronteira, 1997. 912 p.

SILVA, L. A. F.; MENEZES, L. B.; BATISTA, A. S.; SILVA, E. B.; TRINDADE, B. R.; FIORAVANTI, M. C. S.; TRINDADE, A. M.; BRITO, A. B. Comparação do método da amputação do II e III metacarpianos (pinioning) e da termocauterização para coibir o voo em pombos (Columbia livia). Ciência Animal Brasileira, Goiânia v. 4, n. 1, p. 85-90, 2003.

STURKIE, P. D.; WHITTOW, G. C. Sturkie's Avian Physiology. 5 ed. California: Academic Press, 2000. 685 p.

YASUDA, M. The anatomical atlas of Gallus. 1. ed. Tokio: University of Tokyo Press, 2004. 464 p. 